\title{
Thyroid Gland Anaplastic Carcinoma
}

National Cancer Institute

\section{Source}

National Cancer Institute. Thyroid Gland Anaplastic Carcinoma. NCI Thesaurus. Code C3878.

A primary carcinoma of the thyroid gland composed of undifferentiated cells. The malignant cells demonstrate evidence of epithelial differentiation, either by immunohistochemistry or electron microscopic studies. Microscopically, in the majority of cases there is a mixture of spindle, epithelioid, and giant cells. The vast majority of the patients present with a rapidly enlarging neck mass. The clinical course is usually aggressive. 